\title{
Age-Dependent Cardiovascular Effects of Verapamil in Newborn Swine
}

\author{
MARISA JARENWATTANANON, BARBARA J. BUCKLEY, NORMAN GOOTMAN, AND \\ NANCY A. KAPLAN \\ Division of Pediatric Cardiology, Schneider Children's Hospital of Long Island Jewish Medical Center, \\ New Hyde Park, New York 11042
}

\begin{abstract}
Since there are limited studies concerning the hemodynamic effects of verapamil in pediatric patients, cardiovascular effects of clinical doses $(100$ or $300 \mu \mathrm{g} / \mathrm{kg})$ of verapamil, given as a 2 -min intravenous infusion, were examined in sodium pentobarbital anesthetized swine, aged 1 day $(n=15)$ and 2 wk $(n=18)$. Aortic and left ventricular pressures, index of left ventricular contractility, heart rate, and phasic superior mesenteric, renal, and femoral arterial flows were recorded; mean aortic pressure and vascular resistances were calculated. Maximum changes in cardiovascular function (mean $\% \Delta \pm \mathrm{SEM}$ ) occurred at the end of the infusion. Mean aortic pressure and index of left ventricular contractility decreased in all animals; responses were larger in magnitude with the higher dose. By $30 \mathrm{~min}$ after infusion of $300 \mu \mathrm{g} / \mathrm{kg}$ verapamil had ended, mean aortic pressure in both 1 day and 2 wk olds and index of left ventricular contractility and femoral flow in 1 day olds were still decreased. During infusion of verapamil, heart rate decreased $(-11.6 \pm 2.9)$ to the high dose in 1 day olds but increased $(+6.4 \pm 2.7)$ to 100 and $300 \mu \mathrm{g} / \mathrm{kg}$ verapamil in 2 wk olds. After infusion of $300 \mu \mathrm{g} / \mathrm{kg}$ verapamil ended, heart rate decreased and reached the nadir $(-10.0 \pm 2.9)$ by $10 \mathrm{~min}$ in 2 wk olds. Decreases in renal resistance $(-7.6$ \pm 1.7 ) were not dose dependent while superior mesenteric resistance decreased $(-12.9 \pm 2.7)$ only to low dose verapamil in 2 wk olds. In 1 day olds decreases in renal and superior mesenteric resistance were not sustained throughout the infusion. The results indicate that verapamil has both age- and dose-dependent cardiovascular effects in newborn swine and suggest that verapamil be used with caution in infants. (Pediatr Res 20: 428-432, 1986)
\end{abstract}

\section{Abbreviations}

AoP, aortic pressure

$\overline{\mathrm{AoP}}$, mean aortic pressure

ECG, electrocardiogram

HR, heart rate

LV, left ventricular

$L V$ dP/dt max, index of $L V$ contractility

$R$, resistance

iv, intravenous
While verapamil is widely used in children and infants for the treatment of supraventricular tachycardia (1-5), adverse effects such as profound hypotension and arterioventricular block have been reported $(1,4,6,7)$. In piglets (aged $18 \pm 6$ days) with hypoxic pulmonary hypertension, verapamil infusion $(150 \mu \mathrm{g} /$ $\mathrm{kg}$ over $2 \mathrm{~min}$ ) decreased systemic and pulmonary artery pressures (8). In puppies a bolus injection of $400 \mu \mathrm{g} / \mathrm{kg}$ verapamil reduced stroke volume and blood flow velocities in aorta and carotid and femoral arteries (9); these effects were not observed in adult dogs.

Since there is little information available concerning the cardiac and regional circulatory effects of verapamil in the newborn period (8-10), we undertook to study the hemodynamic responses to verapamil in two ages of young swine to further the understanding of the pharmacology of verapamil in pediatrics as a function of postnatal development.

\section{MATERIALS AND METHODS}

Animal preparation. Two age groups of neonatal swine were used in this study: 1 day ( $\leqslant 24$ h old; $n=15)$ and 2 wk $(12-16$ days; $n=8)$. These two age groups have previously been demonstrated to have clear age-related differences in cardiovascular responses to various pharmacologic agents and to physiologic interventions (11-15). Animals were anesthetized with intraperitoneal sodium pentobarbital $(18$ and $25 \mathrm{mg} / \mathrm{kg}$ for the 1 day and 2 wk olds, respectively) (12). Supplemental doses of sodium pentobarbital were administered iv at one-tenth the initial dose, as needed throughout the experimental protocol. For a more detailed description of the general methodology, the reader is referred to our previous work $(13,16)$. Body temperature, hydration, arterial blood gases, and $\mathrm{pH}$ were maintained and the animals were artificially ventilated. A catheter was inserted in an external jugular vein for injections and in a femoral artery for measurement of AoP. Decamethonium bromide was administered in doses of $1 \mathrm{mg} / \mathrm{kg}$ iv to minimize muscle tremor artifacts on the recordings. The LV was catheterized with the shortest end-hole catheter possible via the left common carotid artery and the first derivative of intraventricular pressure $(\mathrm{LV} \mathrm{dP} / \mathrm{dt})$ was obtained through electronic differentiation. Statham electromagnetic flow probes were placed around the superior mesenteric, a femoral and a renal artery as in our standard preparation (13). The ECG, HR, AoP, flows, LVP, and LV dP/dt were continuously recorded on a Beckman $\mathrm{R} 611$ dynograph. A change in $\mathrm{LV} \mathrm{dP} / \mathrm{dt}$ max was used as the index of inotropic response.

Protocol. Following completion of surgical procedures, cardiovascular and blood gas parameters were stabilized for a period of $1 \mathrm{~h}$. Verapamil (Isoptin, racemic mixture, from Knoll Pharmaceutical) in the doses of 100 or $300 \mu \mathrm{g} / \mathrm{kg}(1,4)$ was administered as a $2-\mathrm{min}$ iv infusion. Only one dose was given in each animal and then observations were made for $30 \mathrm{~min}$ after the infusion ended.
Reprint requests Norman Gootman, M.D., Pediatric Cardiology, Schneider Children's Hospital, Long Island Jewish Medical Center, New Hyde Park, NY 11042.

Address for correspondence Norman Gootman, M.D., Pediatric Cardiology, Schneider Children's Hospital, Long Island Jewish Medical Center, New Hyde Park, NY 11042.

This work was supported by awards from the American Heart Association, Nassau Chapter and Long Island Jewish Medical Center 
Table 1. Initial control conditions (mean \pm SEM) in developing swine anesthetized with sodium pentobarbital

\begin{tabular}{lcc}
\hline & Day $(n=15)$ & $2 \mathrm{Wk}(n=18)$ \\
\hline $\mathrm{HR}(\mathrm{bpm})$ & $224.0 \pm 8.3$ & $234.3 \pm 7.8$ \\
$\mathrm{LV} \mathrm{dP} / \mathrm{dt}(\mathrm{mm} \mathrm{Hg} / \mathrm{ms})$ & $3.3 \pm 0.3$ & $3.1 \pm 0.2$ \\
$\overline{\text { AoP }}(\mathrm{mm} \mathrm{Hg})$ & $63.9 \pm 2.4$ & $94.2 \pm 3.0^{*}$ \\
Mesenteric flow $(\mathrm{ml} / \mathrm{min})$ & $49.6 \pm 10.7$ & $121.7 \pm 15.8^{*}$ \\
Renal flow (ml/min) & $10.8 \pm 1.0$ & $33.6 \pm 3.8^{*}$ \\
Femoral flow (ml/min) & $9.8 \pm 1.3$ & $22.0 \pm 2.8^{*}$ \\
Mesenteric R (PRU) $\dagger$ & $1.8 \pm 0.2$ & $1.0 \pm 0.1^{*}$ \\
Renal R (PRU) & $6.6 \pm 0.7$ & $3.5 \pm 0.4^{*}$ \\
Femoral R (PRU) & $8.1 \pm 1.0$ & $5.8 \pm 0.9^{*}$ \\
Body wt (kg) & $1.5 \pm 0.6$ & $2.6 \pm 0.2^{*}$ \\
\hline
\end{tabular}
$0.05)$

* Significantly different from 1-day-old group by unpaired $t$ test ( $p \leq$ $\dagger$ Peripheral resistance units.

Calculations. HR (bpm) was obtained from the calibrated cardiotachometer. $\overline{\mathrm{AoP}}(\mathrm{mm} \mathrm{Hg})$ was calculated as one-third (systolic pressure +2 times diastolic pressure). Mean flow ( $\mathrm{ml} /$ min) was calculated with the aid of a systolic:diastolic flow ratio (0.43) established by the electronic mean. Regional vascular $\mathrm{R}$ were calculated from the ratio of $\overline{\mathrm{AOP}} /$ mean flow and expressed as peripheral resistance units. LVP and $\mathrm{LV} \mathrm{dP} / \mathrm{dt}(\mathrm{mm} \mathrm{Hg} / \mathrm{ms})$ were recorded and $\mathrm{dP} / \mathrm{dt}$ max was measured directly.

Each cardiovascular parameter was calculated as percent change from the initial preinfusion control value, at 20 -s intervals during the infusion, at 1 -min intervals for the first $5 \mathrm{~min}$ after the end of the infusion, and then at 5-min intervals until $30 \mathrm{~min}$ after the infusion ended.

Statistical analysis. Each animal served as its own control for all observations on the effects of experimental interventions. Percent change of each cardiovascular parameter was used to evaluate any age-related effects of verapamil, since control values were age dependent (Table 1), as previously reported $(8,12,16$, 17). Control values were compared between the two age groups using the unpaired $t$ test (18). Changes in cardiovascular function from baseline in response to verapamil administration (presented in Figs. 2-4) were calculated as percent change and compared with zero change by the paired sample $t$ test to establish the statistical significance of the observed change and reported as $\% \Delta \overline{\mathrm{X}} \pm \mathrm{SEM}$. For the percent changes in each cardiovascular parameter at the end of the 2-min infusion, the time when maximum changes occurred (Figs. 2-4), the following crosscomparisons were made using the unpaired $t$ test: 1) between the two doses of verapamil administered at a given age, 2) between the two age groups at a given dose. For all of these the null hypothesis for a two-tailed distribution was rejected at $p$ values $\leqslant 0.05(18)$ (the $p$ values for the unpaired $t$ tests are presented in the text).

\section{RESULTS}

The initial control values of cardiovascular function are presented in Table 1. There were age-related increases in $\overline{\mathrm{AoP}}$, body weight, and regional blood flow and decreases in peripheral vascular $\mathrm{R}$, except femoral $\mathrm{R}$ as we have previously reported for developing swine $(12,13)$.

Figure 1 shows the cardiovascular responses to $300 \mu \mathrm{g} / \mathrm{kg}$ verapamil in a representative 1-day-old piglet. All cardiovascular parameters decreased after infusion of high dose verapamil in swine at birth.

Cardiovascular responses to verapamil infusion are summarized in Figures 2-4. Maximum changes in cardiovascular function occurred at the end of the 2-min infusion. By 30 min after the infusion ended, most cardiovascular parameters returned to the baseline level; exceptions are indicated below.

$\overline{\mathrm{AoP}}$ decreased in all animals during infusion of verapamil (Fig. 2, upper panel); this decrease was significantly larger with

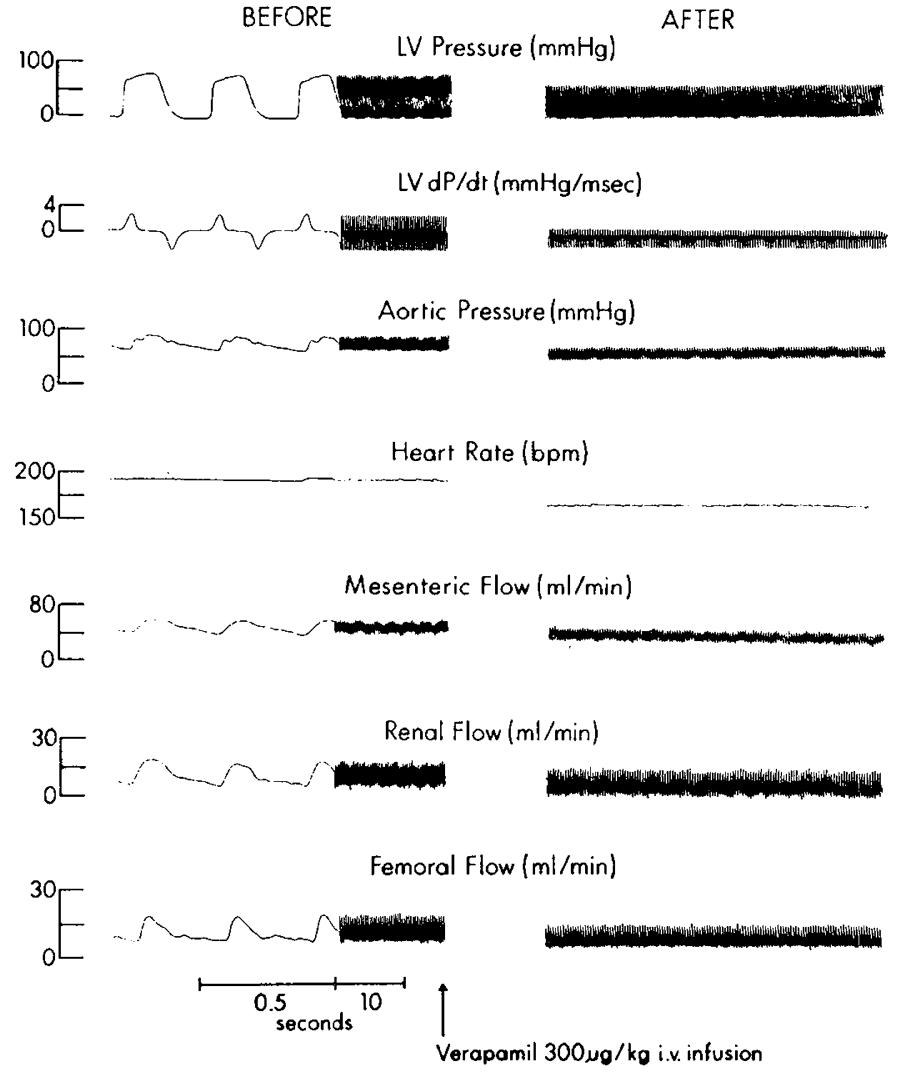

Fig. 1. Original polygraph recordings of cardiovascular parameters before (left panel) and after (right panel) a 2-min infusion of high dose verapamil in a representative 1 -day-old piglet.
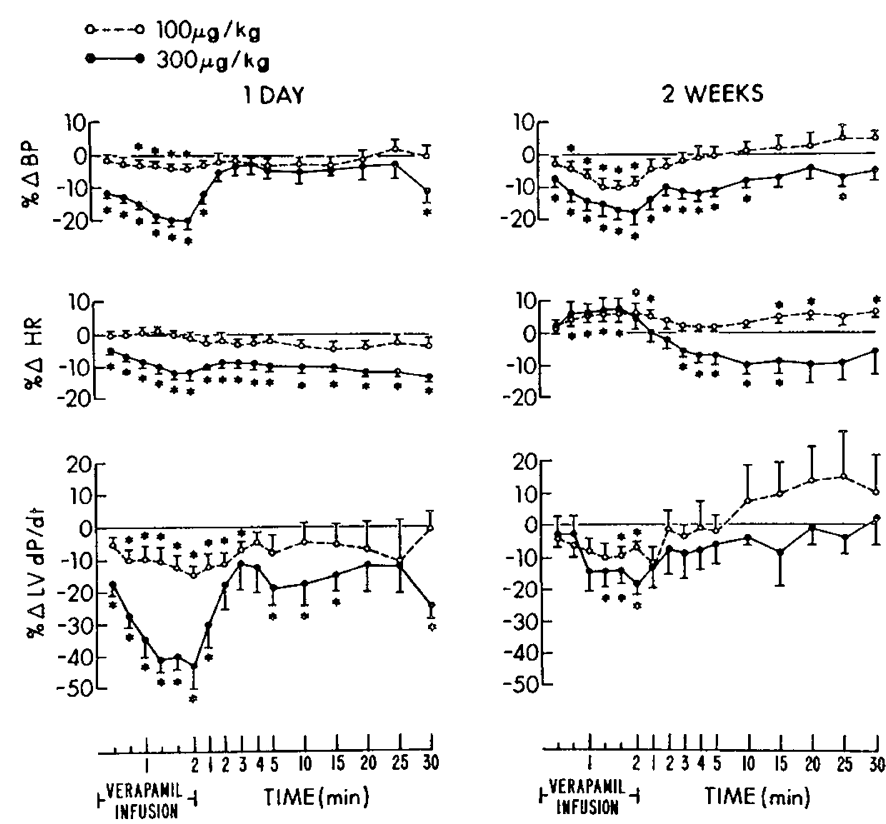

Fig. 2. Age- and dose-related differences in the effect of verapamil on $\overline{\mathrm{AOP}}$ (upper panel), HR (middle panel), and $\mathrm{LV} \mathrm{dP} / \mathrm{dt}$ (lower panel) in 1-day (left panel) and 2-wk-(right panel) old swine. Mean percent change $(\% \Delta) \pm$ SEM (ordinate) during a $2-$ min infusion of 100 or $300 \mu \mathrm{g} / \mathrm{kg}$ verapamil and for $30 \mathrm{~min}$ after verapamil infusion (abscissa). Asterisks indicate mean $\% \Delta$ significantly different from zero change $(p \leqslant 0.05)$.

the high dose than with the low dose in either age group ( $p \leqslant$ 0.0002 and $\leqslant 0.04$ for the 1 day and 2 wk olds, respectively). With the low dose of verapamil, there was a significantly larger $(p \leqslant 0.03)$ decrease in $\overline{\mathrm{AoP}}$ in the 2 -wk-old group than in the 1 - 

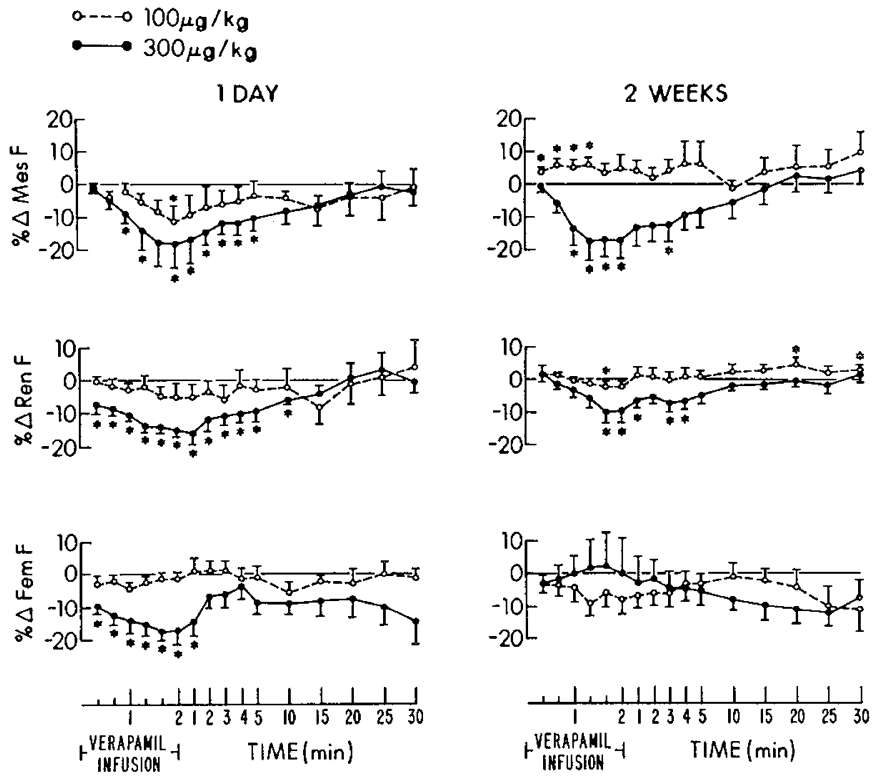

Fig. 3. Age-and dose-related differences in the effect of verapamil on Mes (superior mesenteric; upper panel), Ren (renal; middle panel), and Fem (femoral; lower panel) flow (F) in 1-day (left panel) and 2-wk- (right panel) old swine. Mean percent change $(\% \Delta) \pm$ SEM (ordinate) during a 2 -min infusion of 100 or $300 \mu \mathrm{g} / \mathrm{kg}$ verapamil and for $30 \mathrm{~min}$ after verapamil infusion (abscissa). Asterisks indicate mean $\% \Delta$ significantly different from zero change $(p \leqslant 0.05)$.
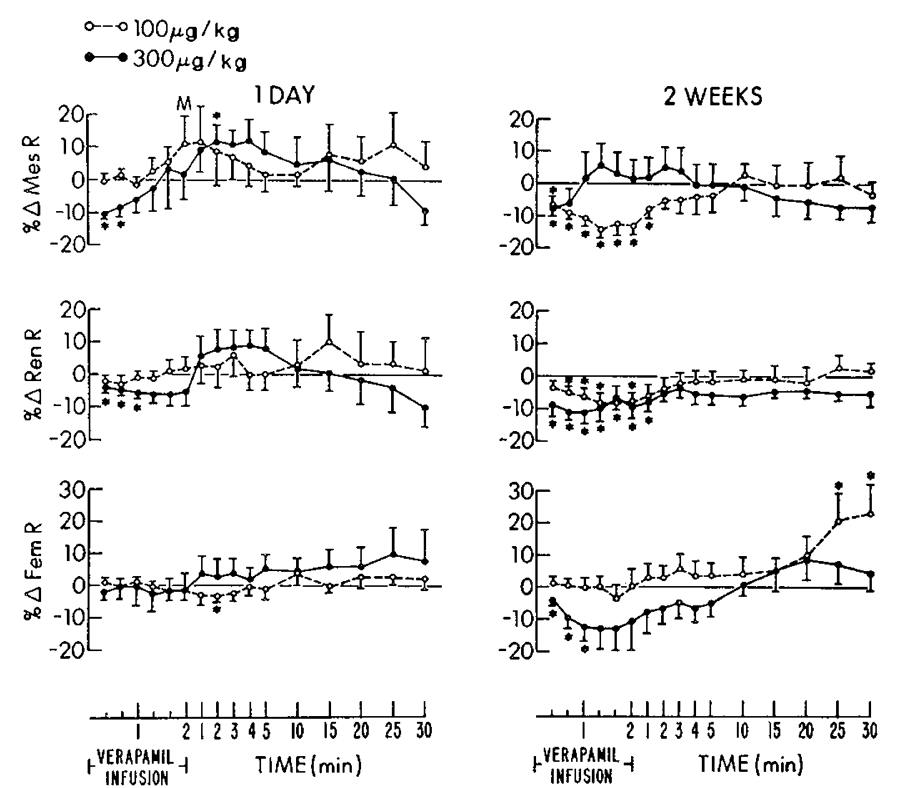

Fig. 4. Age- and dose-related differences in the effect of verapamil on Mes (superior mesenteric; upper panel), Ren (renal; middle panel), and Fem (femoral; lower panel) resistance (R) in 1-day (left panel) and 2-wk(right panel) old swine. Mean percent change $(\% \Delta) \pm$ SEM (ordinate) during a 2-min infusion of 100 or $300 \mu \mathrm{g} / \mathrm{kg}$ verapamil and for $30 \mathrm{~min}$ after verapamil infusion (abscissa). Asterisks indicate mean $\% \Delta$ significantly different from zero change $(p \leqslant 0.05)$.

day-old group. Immediately following the end of verapamil infusion, $\overline{\mathrm{AoP}}$ started to return toward baseline level in both age groups.

HR decreased in 1-day-old piglets after $300 \mu \mathrm{g} / \mathrm{kg}$ verapamil, but did not change after $100 \mu \mathrm{g} / \mathrm{kg}$ verapamil (Fig. 2, left middle panel); the effects of the two doses of verapamil on HR were significantly different $(p \leqslant 0.002)$. In contrast, in the 2-wk-old group HR increased during infusion of both doses of verapamil; after the end of the infusion HR then decreased from control only in the animals given $300 \mu \mathrm{g} / \mathrm{kg}$ verapmil (Fig. 2 right middle panel). The effect of verapamil on HR was age dependent for $100 \mu \mathrm{g} / \mathrm{kg}(p \leqslant 0.05)$ and for $300 \mu \mathrm{g} / \mathrm{kg}(p \leqslant 0.006)$.

$\mathrm{LV} \mathrm{dP} / \mathrm{dt}$ max decreased in all animals with verapamil (Fig. 2, lower panel); the decrease was larger with $300 \mu \mathrm{g} / \mathrm{kg}$ than with $100 \mu \mathrm{g} / \mathrm{kg}$ verapamil in either age group $(p \leqslant 0.004$ and 0.02 for the 1 day and 2 wk olds, respectively). Negative inotropic responses were larger in the 1 day olds than in the $2 \mathrm{wk}$ olds with either $100 \mu \mathrm{g} / \mathrm{kg}(p \leqslant 0.03)$ or $300 \mu \mathrm{g} / \mathrm{kg}(p \leqslant 0.02)$. By $30 \mathrm{~min}$ after infusion of verapamil, $\mathrm{LV} \mathrm{dP} / \mathrm{dt}$ max returned toward the baseline level except in the 1 day olds given $300 \mu \mathrm{g} / \mathrm{kg}$ verapamil (Fig. 2, left lower panel).

The effects of verapamil on peripheral circulation are presented in Figures 3 (flows) and 4 (resistances). Superior mesenteric flow decreased in all animals receiving $300 \mu \mathrm{g} / \mathrm{kg}$ verapamil (Fig. 3, upper panel). Superior mesenteric flow increased in the older animals during the first min of $100 \mu \mathrm{g} / \mathrm{kg}$ verapamil infusion, but not in the younger animals. The effect of verapamil on superior mesenteric flow was dose dependent in the older animals $(p \leqslant 0.008)$ and age-dependent with respect to the low dose $(p \leqslant$ 0.01 ). Renal flow decreased with the high dose of verapamil in both age groups (Fig. 3, middle panel); there was no significant change in renal flow with the low dose. By $30 \mathrm{~min}$ after the end of the infusion, restoration of superior mesenteric and renal flow occurred in all animals.

Femoral flow decreased significantly in the 1 day olds with infusion of $300 \mu \mathrm{g} / \mathrm{kg}$ verapamil (Fig. 3, left lower panel), but did not change with infusion of $100 \mu \mathrm{g} / \mathrm{kg}$ verapamil. Administration of either dose of verapamil did not significantly alter femoral flow in the 2-wk-old animals. Femoral flow remained low throughout the 30 -min observation period in 1 day olds receiving $300 \mu \mathrm{g} / \mathrm{kg}$ verapamil.

Mesenteric and renal $\mathrm{R}$ decreased during the first min of the $300 \mu \mathrm{g} / \mathrm{kg}$ infusion in 1 day olds as illustrated in Figure 4, left panel; these effects were not sustained. However, in 2-wk old animals, the decreases in renal $\mathrm{R}$ (to both doses) and mesenteric $\mathrm{R}$ (to $100 \mu \mathrm{g} / \mathrm{kg}$ ) were maintained throughout the infusion (Fig. 4, right panel). In contrast, a trend toward an increase in mesenteric $\mathrm{R}$ was observed in all 1-day-old animals by the end of the verapamil infusion; however, only one point was statistically significant. There was no significant change in femoral $\mathrm{R}$ in response to either dose in 1-day-old piglets; however, a significant decrease in femoral $\mathrm{R}$ was observed to $300 \mu \mathrm{g} / \mathrm{kg}$ verapamil in 2 wk olds but was not sustained. All resistances always returned toward control levels by $30 \mathrm{~min}$ with one exception; there was an unexplained increase in femoral $\mathrm{R}$ in 2 wk olds given 100 $\mu \mathrm{g} / \mathrm{kg}$ verapamil.

\section{DISCUSSION}

The animals in our study were anesthetized with pentobarbital. Despite our concern of the possible vulnerability of the developing cardiovascular and nervous systems to this anesthetic agent, the cardiovascular effects of exogenous catecholamines in pentobarbital anesthetized piglets are similar to those in decerebrate preparations (12) and regional vascular responses to direct and reflex stimulation are active (11). Furthermore, there were no significant differences in the initial and final cardiovascular control values in pentobarbital anesthetized piglets (12). In conscious animal preparations there are always changes in physical and emotional activity which may lead to changes in plasma catecholamine level. Although our anesthetized piglet may not be representative of an intact unanesthetized animal, conscious preparations may also be affected by factors which complicate analysis of results.

Verapamil is a coronary and peripheral vasodilator (19-21) which has direct chronotropic and inotropic effects on the myo- 
cardium $(19,20,22)$ in adult animals. Low doses of this calcium channel blocking agent cause peripheral vasodilation; the resulting hypotension leads to reflex tachycardia and a reflex increase in left ventricular contractility index (23). However, with higher doses of verapamil, direct negative inotropic and chronotropic effects cannot be overcome by reflex increases in sympathetic tone. In $20-\mathrm{kg}$ swine (approximately 2 months of age) (17) anesthetized with $1 \%$ halothane, verapamil did not elicit changes in HR (24); this may be due to the depressant effect of this concentration of halothane on the baroreceptor reflex. In our experiments in developing swine, the time course data show clearly that a similar degree of hypotension in both age groups was accompanied by tachycardia only in the 2 wk olds; this reflex response has also been reported in adults (23). Furthermore, the negative inotropic effect of the high dose of verapamil was much smaller in the older than in the younger animals and there was no compensatory increase in LV contractility index in either age group, as has been reported in adult mammals (23). We concluded that reflex-induced compensation had not occurred in newborns.

The lack of compensatory responses to the hypotensive and negative inotropic effects of verapamil in the young piglets could be due to a number of different factors. The adrenergic effector system at the sinoatrial node and myocardium has been shown to be considerably less sensitive to its neurotransmitter at birth as compared to older piglets and maturation of chronotropic and inotropic responses to norepinephrine continue through the 1st wk of life (12). Therefore, the lack of compensatory responses could be explained by functional immaturity of the cardiac adrenergic effector system at birth. Cardiac output of young animals may be more dependent on HR than that of adult animals (25). Thus the newborn animals may be limited in their ability to regulate cardiac output by changes in stroke volume. The absence of vasodilation to augment myocardial function may also contribute. Other factors could be greater sensitivity to verapamil in younger animals and/or immaturity of central and peripheral sympathetic cardiovascular regulation in the newborns (17)

While there are numerous studies in adults on the vasodilator effect of verapamil on regional circulations $(20,22)$, there is little information available in the newborn (9). In anesthetized puppies, verapamil $(400 \mu \mathrm{g} / \mathrm{kg})$, given as a bolus injection, decreased velocity of flow in the aorta, carotid, and femoral arteries in contrast to responses in adult dogs (9). The present study is the only one, to the best of our knowledge, in which the effect of verapamil on the renal and superior mesenteric circulation was examined in neonates. A decrease in renal and superior mesenteric $\mathrm{R}$ was observed in 2-wk-old piglets following the low dose of verapamil, and a decrease in renal and femoral $\mathrm{R}$ followed the high dose of verapamil (Fig. 4). In contrast, peripheral vascular $\mathrm{R}$ did not change significantly in 1-day-old piglets except for the initial transient decreases in renal and superior mesenteric $\mathrm{R}$ during infusion of the high dose of verapamil. In these young animals, peripheral flows decreased (Fig. 3) almost passively with the AoP decrease (Fig. 2) during infusion of high dose verapamil. As expected, the pattern of response was not the same in each of the three vascular beds (Figs. 3 and 4), especially in the older animals. Our data suggest that the ability of verapamil to elicit peripheral vasodilation matures postnatally.

Studies in adults have shown that verapamil has blocking properties at calcium-dependent $\alpha$ adrenoceptors in peripheral vascular beds (25) leading to vascular relaxation $(19,26)$. Immaturity of adrenergic response in different vascular beds at birth has been previously demonstrated (11). Preliminary results from our laboratory suggest that calcium-dependent $\alpha$ adrenoceptors in peripheral vascular beds of swine mature postnatally (27). We therefore, speculate that the age-related differences in direct effects of verapamil on peripheral vasculature (Figs. 3 and 4) may be due, in part, to immaturity of calcium-dependent $\alpha$ adrenoceptors.
Our present results indicate that verapamil produces greater negative inotropic and chronotropic effects and less peripheral vasodilation in piglets at birth than later in postnatal life and that the newborns are incapable of reflex increases in sympathetic discharge to the heart. The difference in cardiovascular responses to verapamil in young swine compared to adults may be due, in part, to immaturity of both central and peripheral cardiovascular regulation $(14,17)$, to greater sensitivity of the myocardium to verapamil in newborn swine, and/or to lesser cardiovascular reserve in the newborn $(25,28)$.

Acknowledgments. The authors gratefully acknowledge the technical assistance of Ms. Barbara J. Peterson and Mr. Peter G. Griswold and thank Dr. Phyllis M. Gootman for critically reviewing and Ms. Marge Lager for typing this manuscript and Knoll Pharmaceutical for supplying the verapamil used in this investigation.

\section{REFERENCES}

1. Greco R, Musto B, Arienzo V, Alborino A, Garofalo S, Marisco F 1982 Treatment of paroxysmal supraventricular tachycardia in infancy with digitalis, adenosine-5'-triphosphate and verapamil: a comparative study. Circulation 66:504-508

2. Porter CJ, Gillette PG, Garson A, Hesslein PS, Karpawich PP, McNamara DG 1981 Effects of verapamil on supraventricular tachycardia in children. Am J Cardiol 48:487-491

3. Sapire DW, O'Riordan AC, Black IFS 1981 Safety and efficacy of short and long term verapamil therapy in children with tachycardia. Am J Cardiol 48:1091-1097

4. Shahar E, Barzilay Z, Frand M 1981 Verapamil in the treatment of paroxysmal supraventricular tachycardia in infants and children. J Pediatr 98:323-326

5. Soler-Soler J, Sagrista-Sauleda J, Cabrera A, Sauleda-Pares J, Iglesias-Berengue J, Permanyer-Miralda G, Roca-Llop J 1979 Effect of verapamil in infants with paroxysmal supraventricular tachycardia. Circulation 59:876-879

6. Apitz J, Gaissmaier U 1971 Zwischenfall mit todlichem Ausgang nach intravenoser Injektion von Isoptin ${ }^{\circledR}$. Med Klin 66:751-755

7. Abinader E, Borochowitz Z, Berger A 1981 A hemodynamic complication of verapamil therapy in a neonate. Helv Paediatr Acta 36:451-455

8. Dickstein PJ, Trindade O, Goldberg RN, Bancalari E 1984 The effect of calcium antagonist on hypoxic pulmonary hypertension in the piglet. Pediat Res 18:1262-1265

9. Gibson R, Driscoll D, Gillette P, Hartley C, Entman ML 1981 The comparative electrophysiologic and hemodynamic effects of verapamil in puppies and adult dogs. Dev Pharmacol Ther 2:104-116

10. Boucek RJ, Shelton M, Artman M, Mushlin PS, Starnes VA, Olson RD 1984 Comparative effects of verapamil, nifedipine, and diltiazem on contractile function in the isolated immature and adult rabbit heart. Pediatr Res 18:948952

11. Buckley NM, Brazeau P, Gootman PM 1983 Maturation of circulatory responses to adrenergic stimuli. Fed Proc 42:1643-1647

12. Buckley NM, Gootman PM, Yellin EL, Brazeau P 1979 Age-related cardiovascular effects of catecholamines in anesthetized piglets. Circ Res 45:282292

13. Gootman N, Buckley BJ, Gootman PM, Griswold PG, Mele JD, Nudel DB 1983 Maturation related differences in regional circulatory effects of dopamine infusion in swine. Dev Pharamcol Ther 6:9-22

14. Gootman PM 1983 Neural regulation of cardiovascular function in the perinatal periods. In: Gootman N, Gootman PM (eds) Perinatal Cardiovascula Function. Marcel Dekker, Inc., New York, pp 265-368

15. Buckley NM, Gootman PM, Gootman N, Reddy GD, Weaver LC, Crane LA 1976 Age-dependent cardiovascular effects of afferent stimulation in neonatal pigs. Biol Neonate 30:268-279

16. Gootman N, Buckley BJ, Gootman PM, Nagelberg JS 1982 Age-related effects of single injections of dopamine on cardiovascular function in developing swine. Dev Pharmacol Ther 4:139-150

17. Gootman PM, Gootman N, Turplapaty PDMV, Yao AC, Buckley BJ, Altura BM 1981 Autonomic regulation of cardiovascular function in neonates. In: Burnstock G (ed) Development of Autonomic Nervous System (Ciba Foundation Symposium 83). Pitman Medical, London, pp 70-93

18. Snedecor GW, Cochran WC 1980 Statistical Methods. Iowa State University Press, Ames, IA

19. Braunwald E 1982 Mechanism of action of calcium-channel-blocking agents N Engl J Med 307:1618-1627

20. O'Hara N, Ono $H$, Oguro K, Hashimoto K, 1981 Vasodilating effects of perhexiline, glyceryl trinitrate and verapamil on the coronary, femoral, renal and mesenteric vasculature of the dog. $\mathbf{J}$ Cardiovasc Pharmacol 3:251-268

21. Zsoter TT, Church JG 1983 Calcium antagonists: pharmacodynamic effects and mechanism of action. Drugs 25:93-112

22. Stone PH, Antman EM, Muller JE, Braunwald E 1980 Calcium channel blocking agents in the treatment of cardiovascular disorders Part II: hemodynamic effects and clinical applications. Ann Intern Med 93:886-904 
23. Angus JA, Richmond DR, Dhumma-Upakorn P, Cobbin LB, Goodman AH 1976 Cardiovascular action of verapamil in the dog with particular reference to myocardial contractility and atrioventricular conduction. Cardiovasc Res 10:623-632

24. Kates RA, Zaggy AP, Norfleet EA, Heath KR 1984 Comparative cardiovascular effects of verapamil, nifedipine, and diltiazem during halothane anesthesia in swine. Anesthesiology 61:10-18

25. Klopfenstein HS, Rudolph AH 1978 Postnatal changes in the circulation and responses to volume loading in sheep. Circ Res 42:839-845

26. Bou J, Llenas J, Massingham R 1983 Calcium entry blocking drugs, "calcium antagonists" and vascular smooth muscle function. J Auton Pharmac 3:219232

27. Jarenwattananon M, Gootman N, Buckley BJ, Kaplan NA, Griswold PG Gootman PM 1985 Effects of a calcium antagonist on the cardiovascular responses to alpha, adrenoceptor agonist in developing swine. Pediatr Res 19(part 4): 174A(abstr)

28. Friedman WF 1973 The intrinsic physiologic properties of the developing heart. In: Friedman WF, Lesch M, Sonnenblick EH (eds) Neonatal Heart Disease. Grune and Stratton, Inc. New York, pp 21-49 